\title{
The occurrence in the migratory locust, Locusta migratoria (Orthoptera: Acrididae), of a short-winged morph with no obvious fitness advantages over the long-winged morph
}

\author{
YudAI NISHIDE and SEIJI TANAKA
}

Locust Research Laboratory, National Institute of Agro-biological Sciences at Ohwashi, Tsukuba, Ibaraki 305-8634, Japan; e-mail: nishiyu0@yahoo.co.jp

Key words. Orthoptera, Acrididae, Locusta migratoria, adaptive significance, trade-off, wing dimorphism

\begin{abstract}
A short-winged morph, whose occurrence is controlled by a simple recessive Mendelian unit, was recently discovered in Locusta migratoria. The existence of trade-offs between flight capability associated with wing length and other fitness-related traits are often documented for insects. The present study investigated the evolutionary significance of the short-winged and long-winged morphs of this locust using two laboratory strains showing wing dimorphism. The life-history traits examined included nymphal development, adult body weight, percentage adult survival, age at first reproduction, egg production and hatchling body weight. The results indicate that there are no consistent morph-specific differences in any of these traits. Of the several possibilities considered, the most likely is that the short-winged morph of this locust is an aberration or represents an initial stage in the evolution of this species.
\end{abstract}

\section{INTRODUCTION}

Intra-specific wing length polymorphism and polyphenism are widespread among insects (Harrison, 1980; Dingle, 1985; Pener, 1985; Tauber et al., 1986; Roff \& Fairbairn, 1991; Zera \& Denno, 1997). This widespread occurrence strongly suggests that fitness is associated with wing length. The most obvious advantage associated with this trait is flight capability, which confers advantages in terms of dispersal and finding food and mates (Rankin, 1985; Danthanarayana, 1986). On the other hand, reduced wings result in a loss of flight capability, which appears not to be advantageous. However, insects that cannot fly sometimes have a higher fitness. Negative correlations or trade-offs between dispersal capability and reproduction are often detected (Zera \& Denno, 1997; Guerra, 2011). In individuals without flight capability, the energy otherwise allocated to construct long wings, flight muscles and production of fuel is available for reproduction. In fact, many studies have shown that the shortwinged morphs have significantly higher fecundity than long-winged morphs in many insects such as grasshoppers (Ritchie et al., 1987), crickets (Tanaka, 1976, 1986, 1993, 1999; Roff, 1984; Mole \& Zera, 1994), planthoppers (Denno \& Grissell, 1979; Denno et al., 1989), aphids (Dixon \& Howard, 1986), seed bugs (Solbreck, 1986; Tanaka \& Wolda, 1987), water striders (Zera, 1984), water bugs (Muraji \& Nakasuji, 1988) and a tussock moth (Sato, 1977; Kimura \& Masaki, 1977). Furthermore, age at first reproduction is delayed in the long-winged morphs of grasshoppers (Ando \& Hartley, 1982; Ritchie et al., 1987; Higaki \& Ando, 2003), crickets (Tanaka, 1976, 1986, 1993; Roff, 1984), aphids (Dixon \& Howard, 1986), planthoppers (Mochida, 1973; Denno et al., 1989), seed bugs (Tanaka \& Wolda, 1987), water striders (Fair- bairn, 1988) and beetles (Utida, 1972). Other costs associated with the long-winged morph include developmental delay (Zera, 1984; Dixon \& Howard, 1986), decreased longevity (Denno et al., 1989) and smaller offspring (Kimura \& Masaki, 1977; Dixon \& Howard, 1986; Solbreck, 1986; Tanaka \& Wolda, 1987).

The migratory locust, Locusta migratoria, is widely distributed in the Old World. Although as many as 10 subspecies are reported for this locust, mainly based on morphological characteristics (Uvarov, 1966; Farrow \& Colless, 1980; Chen, 1999), Tokuda et al. (2010) and Ma et al. (2012), adopting a mitochondrial DNA analysis, suggest that this species may be divided into a southern and northern clade. The southern clade may include populations in Africa, Southern Europe, Australia, South East Asia and the Far East, whereas the northern clade consists of populations in Northern Europe, central and northern China and all regions of Japan except for Okinawa and a few locations on Honshu Island. However, all of these populations consist of long-winged individuals and, as its common name indicates, adults of this species have a high dispersal ability. Recently, short-winged adults were discovered in a Japanese strain of L. migratoria (Tanaka \& Nishide, 2012a). Wing length is controlled by a single recessive Mendelian unit and the pattern in the variation in wing length indicates a wing length dimorphism with short- and long-winged morphs. The short-winged morph has not only shorter wings but also shorter legs than the long-winged morph (Tanaka \& Nishide, 2012a; Nishide \& Tanaka, 2013). The short wings of this morph appear to be due to morphogenetic differentiation rather than a failure of the wings to fully expand. This differentiation, in terms of differences in wing-pad size in the two morphs, is apparent in the penul- 
TABLE 1. Comparison of the duration of nymphal development (mean $\pm \mathrm{SD}$, days) of long- (LW) and short-winged (SW) individuals of L. migratoria.

\begin{tabular}{|c|c|c|c|c|}
\hline & \multicolumn{2}{|l|}{ Tsushima strain } & \multicolumn{2}{|l|}{ Albino strain } \\
\hline & Nymphal development (days) & $\mathrm{n}$ & Nymphal development (days) & $\mathrm{n}$ \\
\hline \multicolumn{5}{|l|}{ (A) Females } \\
\hline $\mathrm{S}^{\dagger}-\mathrm{LW}$ & $29.5 \pm 2.0 \mathrm{c}$ & 21 & $28.5 \pm 3.0 \mathrm{a}$ & 30 \\
\hline $\mathrm{S}^{\dagger}-\mathrm{SW}$ & $30.3 \pm 4.1 \mathrm{c}$ & 29 & $28.4 \pm 4.8 \mathrm{a}$ & 32 \\
\hline $\mathrm{G}^{\dagger}-\mathrm{LW}$ & $23.8 \pm 2.7 \mathrm{a}$ & 105 & $29.8 \pm 2.5 \mathrm{a}$ & 57 \\
\hline $\mathrm{G}^{\dagger}-\mathrm{SW}$ & $25.3 \pm 3.1 b$ & 122 & $29.5 \pm 2.6 \mathrm{a}$ & 83 \\
\hline \multicolumn{5}{|l|}{ (B) Males } \\
\hline $\mathrm{S}^{\dagger}-\mathrm{LW}$ & $27.8 \pm 2.4 b$ & 32 & $26.3 \pm 2.0 \mathrm{a}$ & 26 \\
\hline $\mathrm{S}^{\dagger}-\mathrm{SW}$ & $27.8 \pm 1.9 b$ & 25 & $26.2 \pm 1.8 \mathrm{a}$ & 45 \\
\hline $\mathrm{G}^{\dagger}-\mathrm{LW}$ & $22.2 \pm 1.4 \mathrm{a}$ & 123 & $27.3 \pm 1.3 b$ & 61 \\
\hline $\mathrm{G}^{\dagger}-\mathrm{SW}$ & $22.4 \pm 1.6 \mathrm{a}$ & 182 & $27.5 \pm 1.6 \mathrm{~b}$ & 96 \\
\hline
\end{tabular}

${ }^{\dagger} \mathrm{S}$ and $\mathrm{G}$ mean individuals reared at low (solitarious) and high (gregarious) rearing densities, respectively. Comparison was made for each sex and each strain. The different letters show significant differences at the $5 \%$ level based on Scheffe's test after a two-way ANOVA.

timate nymphal stage. The purpose of the present study is to examine the adaptive significance of the short-winged morph in this locust. We compared developmental traits, such as nymphal growth rate and adult body weight and reproductive traits, including age at first reproduction, percentage survival of adults, number of egg pods produced, number of eggs per egg pod, percentage of the eggs that hatched and hatchling body weight, of long- and short-winged morphs.

Locusts are known to exhibit density-dependent continuous variation called phase polyphenism in which various traits such as behaviour, body colour, morphology and biochemistry vary with population density (Pener \& Simpson, 2009). L. migratoria is one such locust (Faure, 1932; Uvarov, 1966; Pener, 1991). For example, individuals of this locust reared in isolated conditions (solitarious locusts) tend to grow more slowly during the nymphal stage but reproduce earlier than those reared in crowded conditions (gregarious locusts) (Duarte, 1938). In a previous study (Nishide \& Tanaka, 2013), we recorded the differences in the morphology of the short- and long-winged morphs of this species at low and high rearing densities and found that the shortwinged morph displays density-dependent variation similar to that recorded for long-winged individuals. In the present study, we compared fitness-related developmental and reproductive traits of the two wing morphs reared under isolated and crowded conditions.

\section{MATERIAL AND METHODS}

\section{Insects}

The short- and long-winged locusts originated from adult females collected on Tsushima Island, Nagasaki, Japan in 2009 (Tanaka \& Nishide, 2012a). Locusts were reared under either isolated or crowded conditions, as described previously (Nishide $\&$ Tanaka, 2013). The duration of nymphal development, body weight of adults at emergence and their percentage survival over the next 30-day periods were recorded for locusts at both rearing densities. The reproductive traits, including age at first reproduction, number of egg pods produced, number of eggs per egg pod and percentage of eggs that hatched and hatchling body weight were measured by rearing each female with two males of the same wing morph of the same strain in a small cage.

As mentioned above, the Tsushima population undergoes embryonic diapause and eggs need to be chilled for a long time before the embryos will resume development. To make it easier to carry out the experiments, adults of the Tsushima population were crossed with those of an albino strain from Okinawa, and the resulting hybrid strain produced short- and long-winged albino locusts, as did their offspring (Tanaka \& Nishide, 2012a). The population from Okinawa undergoes embryonic diapause only if temperatures are low and the eggs will hatch without undergoing diapause at a high temperature of $30^{\circ} \mathrm{C}$ (Yamagishi \& Tanaka, 2009). In the present study, the eggs from the crossbred locusts (called "albino strain" below) hatched without entering diapause at $30^{\circ} \mathrm{C}$. All traits measured for the Tsushima strain were measured for the albino strain except for adult body weight and survival of adults. The reproductive traits, including the number of egg pods produced and total egg production, were recorded only for those females that reproduced.

\section{Statistical analysis}

The duration of nymphal development and adult body weight were analyzed using Scheffe's test after a two-way ANOVA (wing morph and rearing density as the factors). Reproductive traits of the long- and short-winged morphs were compared using Scheffe's test at a 5\% level of probability. The percentage survival of the long- and short-winged morphs was compared using a chi square test at a $5 \%$ level of probability.

\section{RESULTS}

\section{Developmental traits}

In the Tsushima strain, wing morph influenced the duration of nymphal development in females (ANOVA; F $=6.03 ; \mathrm{df}=1,273 ; \mathrm{P}<0.05)$. In this case, a significant difference was found only for gregarious females (Table 1; Sheffe's test; $\mathrm{P}<0.05)$. In females, nymphal development was significantly influenced by phase (ANOVA; $\mathrm{F}$ $=128.28 ; \mathrm{df}=1,273 ; \mathrm{P}<0.01)$ and was faster in the gregarious than solitarious locusts in both morphs (Table 1). Similar results were obtained for males with no significant difference between the two wing morphs (ANOVA; 
TABLE 2. Comparison of adult body weights (mean $\pm \mathrm{SD}, \mathrm{g}$ ) of long- (LW) and short-winged (SW) individuals of L. migratoria.

\begin{tabular}{ccc}
\hline & \multicolumn{2}{c}{ Tsushima strain } \\
\cline { 2 - 3 } & Adult body weight & $\mathrm{n}$ \\
\hline (A) Females & & \\
\hline $\mathrm{S}^{\dagger}-\mathrm{LW}$ & $1.75 \pm 0.23 \mathrm{~b}$ & 21 \\
$\mathrm{~S}^{\dagger}-\mathrm{SW}$ & $1.70 \pm 0.29 \mathrm{~b}$ & 27 \\
$\mathrm{G}^{\dagger}-\mathrm{LW}$ & $1.56 \pm 0.25 \mathrm{a}$ & 105 \\
$\mathrm{G}^{\dagger}-\mathrm{SW}$ & $1.50 \pm 0.27 \mathrm{a}$ & 122 \\
\hline (B) Males & & \\
\hline $\mathrm{S}^{\dagger}$-LW & $1.05 \pm 0.16 \mathrm{~b}$ & 32 \\
$\mathrm{~S}^{\dagger}-\mathrm{SW}$ & $1.00 \pm 0.12 \mathrm{~b}$ & 25 \\
$\mathrm{G}^{\dagger}-\mathrm{LW}$ & $1.03 \pm 0.10 \mathrm{~b}$ & 123 \\
$\mathrm{G}^{\dagger}-\mathrm{SW}$ & $0.93 \pm 0.10 \mathrm{a}$ & 182 \\
\hline
\end{tabular}

${ }^{\dagger} \mathrm{S}$ and $\mathrm{G}$ are individuals reared at low (solitarious) and high (gregarious) rearing densities, respectively. Comparison was made for each sex and each strain. The different letters show significant differences at the $5 \%$ level based on a Scheffe's test after a two-way ANOVA.

$\mathrm{P}>0.05)$ and development was significantly faster in the gregarious than solitarious locusts in both morphs. In the albino strain, on the other hand, gregarious locusts showed a slightly smaller mean value than the solitarious locusts (ANOVA; $\mathrm{F}=6.72 ; \mathrm{df}=1.198 ; \mathrm{P}<0.05$ ), although the difference was statistically insignificant in males (Table 1; ANOVA; $\mathrm{P}>0.05$ ). In this strain, no significant morph-specific difference was found in either phase in each sex (Table 1; ANOVA; $\mathrm{P}>0.05$ ) and there was no phase-wing morph interaction in this or the other strain (ANOVA; $\mathrm{P}>0.05$ ).

Body weight at adult emergence was recorded only for the Tsushima strain. Wing morph did not significantly influence adult body weight in females (ANOVA; P > $0.05)$. In males, the corresponding difference was significant (ANOVA; $F=7.14$ : $d f=1,363 ; \mathrm{P}<0.05$ ), but a significant morph-specific difference was recorded only for the gregarious males (Table 2, Sheffe's test; $\mathrm{P}<0.01$ ). Solitarious females were significantly heavier than gregarious females in both morphs. In males, there was no significant difference between the long-winged morphs, but solitarious individuals were significantly heavier than gregarious ones in the short-winged morph (Table 2; Sheffe's test; $\mathrm{P}<0.01)$.

\section{Reproductive traits}

The age at first reproduction was compared between the two wing morphs only for gregarious females that were
TABLE 4. Comparison of the percentage of long- (LW) and short-winged (SW) individuals of L. migratoria surviving on the 30th day after adult emergence.

\begin{tabular}{cccc}
\hline & \multicolumn{3}{c}{ Tsushima strain } \\
\cline { 2 - 4 } (A) Females & \multicolumn{3}{c}{ Survival (\%) } \\
\hline $\mathrm{S}^{\dagger}$-LW & 28.6 & n.s. & 21 \\
$\mathrm{~S}^{\dagger}$-SW & 48.2 & & 27 \\
$\mathrm{G}^{\dagger}$-LW & 57.1 & $\mathrm{P}<0.01$ & 105 \\
$\mathrm{G}^{\dagger}$-SW & 42.6 & & 122 \\
\hline (B) Males & & & \\
\hline $\mathrm{S}^{\dagger}$-LW & 18.8 & n.s. & 32 \\
$\mathrm{~S}^{\dagger}$-SW & 20.0 & & 25 \\
$\mathrm{G}^{\dagger}$-LW & 39.8 & n.s. & 123 \\
$\mathrm{G}^{\dagger}$-SW & 41.8 & & 182 \\
\hline
\end{tabular}

${ }^{\dagger} \mathrm{S}$ and $\mathrm{G}$ are individuals reared at low (solitarious) and high (gregarious) rearing densities, respectively. Comparison was made for each sex at each density. The differences were analyzed using a chi square test. n.s. indicates no significant difference at the $5 \%$ level.

each kept with two males of similar age after adult emergence. In both strains, no morph-specific difference was recorded (Table 3, Scheffe's test, $\mathrm{P}>0.05$ ). The percentage survival over the first 30 days after adult emergence was similar between the two wing morphs except for the gregarious females, which suffered a higher percentage mortality than the short-winged morph (Table 4, chi square test, $\mathrm{P}<0.05$ ). The mean number of egg pods deposited during the entire adult stage was approximately 3 or 4 for the Tsushima strain and 6 or 7 for the albino strain, but these differences between the two strains were not statistically different (Scheffe's test, $\mathrm{P}>0.05$ ). The difference between the two wing morphs in each strain was not significant (Table 5, Scheffe's test, $\mathrm{P}>0.05$ ). The number of eggs per egg pod (Table 6) and life time fecundity for females (Table 7) were similar between the two wing morphs (Scheffe's test, $\mathrm{P}>0.05$ ). This was also the case when the results for the females that did not lay any egg-pods or eggs were included in the analysis (data not shown; Scheffe's test, $\mathrm{P}>0.05$ ). The percentage of eggs that hatched of the two wing morphs in both strains did not differ significantly (Table 8). It was higher in the albino than in the Tsushima strain in both wing morphs (Scheffe's test, $\mathrm{P}<0.01$ ). Hatchling body weight for the short-winged morph was significantly lower than that for the Tsushima strain. However, the inter-morph difference was not significant in the albino strain (Table 9).

TABLE 3. Comparison of the age at first reproduction (mean $\pm \mathrm{SD}$, days) of long- (LW) and short-winged (SW) individuals of gregarious L. migratoria.

\begin{tabular}{|c|c|c|c|c|c|}
\hline & \multicolumn{2}{|c|}{ Tsushima strain } & \multicolumn{3}{|c|}{ Albino strain } \\
\hline & Age at first reproduction & $\mathrm{n}$ & Age at first reproduction & & $\mathrm{n}$ \\
\hline LW & $30.0 \pm 4.8$ & 11 & $36.5 \pm 9.6$ & & 14 \\
\hline SW & $30.9 \pm 3.8$ & 10 & $34.6 \pm 6.5$ & n.s. & 9 \\
\hline
\end{tabular}

n.s. indicates significant difference at the $5 \%$ level based on a Scheffe's test. 
TABLE 5. Comparison of the number of egg pods produced (mean \pm SD) by long- (LW) and short-winged (SW) individuals of gregarious L. migratoria.

\begin{tabular}{cccccccc}
\hline & \multicolumn{2}{c}{ Tsushima strain } & & \multicolumn{2}{c}{ Albino strain } \\
\cline { 2 - 3 } & Number of egg pods produced & & $\mathrm{n}$ & & Number of egg pods produced & $\mathrm{n}$ \\
\hline LW & $3.27 \pm 1.42$ & n.s. & 11 & & $5.79 \pm 4.81$ & n.s. & 14 \\
SW & $3.80 \pm 2.20$ & & 10 & & $7.60 \pm 3.20$ & 10 \\
\hline
\end{tabular}

Data are based only on those females that produced at least one egg pod. n.s. indicates no significant difference at the $5 \%$ level using Scheffe's test.

TABLE 6. Comparison of the number of eggs recorded per egg pod (mean $\pm \mathrm{SD}$ ) for long- (LW) and short-winged (SW) individuals of gregarious L. migratoria.

\begin{tabular}{|c|c|c|c|c|c|c|}
\hline & \multicolumn{3}{|c|}{ Tsushima strain } & \multicolumn{3}{|c|}{ Albino strain } \\
\hline & No. of eggs per egg pod & & $\mathrm{n}$ & No. of eggs per egg pod & & $\mathrm{n}$ \\
\hline LW & $34.2 \pm 11.3$ & $\mathfrak{n} s$ & 74 & $45.0 \pm 17.1$ & $n_{\mathrm{s}}$ & 87 \\
\hline SW & $33.7 \pm 13.4$ & n.s. & 59 & $45.4 \pm 15.2$ & n.s. & 91 \\
\hline
\end{tabular}

n.s. indicates no significant difference at the $5 \%$ level based on a Scheffe's test.

TABLE 7. Comparison of the number of progeny produced per female (mean $\pm \mathrm{SD}$ ) by long- (LW) and short-winged (SW) individuals of gregarious L. migratoria.

\begin{tabular}{|c|c|c|c|c|c|c|}
\hline & \multicolumn{3}{|c|}{ Tsushima strain } & \multicolumn{3}{|c|}{ Albino strain } \\
\hline & Total egg production & & $\mathrm{n}$ & Total egg production & & $\mathrm{n}$ \\
\hline LW & $73.46 \pm 37.46$ & \multirow{2}{*}{ n.s. } & 11 & $186.93 \pm 192.16$ & \multirow{2}{*}{ n.s. } & 14 \\
\hline SW & $112.10 \pm 132.28$ & & 10 & $292.80 \pm 183.97$ & & 10 \\
\hline
\end{tabular}

Data include all the females tested. n.s. indicates no significant difference at the $5 \%$ level based on a Scheffe's test.

TABLE 8. Comparison of the percentage of eggs (mean \pm SD) produced by long- (LW) and short-winged (SW) individuals of gregarious L. migratoria that hatched.

\begin{tabular}{|c|c|c|c|c|c|c|}
\hline & \multicolumn{3}{|l|}{ Tsushima strain } & \multicolumn{3}{|l|}{ Albino strain } \\
\hline & Percentage of eggs that hatched (\%) & & $\mathrm{n}$ & Percentage of eggs that hatched (\%) & & $\mathrm{n}$ \\
\hline LW & $62.6 \pm 30.7$ & \multirow{2}{*}{ n.s. } & 74 & $76.1 \pm 19.8$ & \multirow{2}{*}{ n.s. } & 87 \\
\hline SW & $65.4 \pm 33.5$ & & 59 & $80.6 \pm 17.6$ & & 91 \\
\hline
\end{tabular}

n.s. indicates no significant difference at the $5 \%$ level based on Scheffe's test.

TABLE 9. Comparison of the weight of the hatchlings (mean $\pm \mathrm{SD}, \mathrm{mg}$ ) of long- (LW) and short-winged (SW) individuals of gregarious L. migratoria .

\begin{tabular}{|c|c|c|c|c|c|c|}
\hline & \multicolumn{3}{|c|}{ Tsushima strain } & \multicolumn{3}{|c|}{ Albino strain } \\
\hline & Weight of hatchling (mg) & & $\mathrm{n}$ & Weight of hatchling $(\mathrm{mg})$ & & $\mathrm{n}$ \\
\hline LW & $16.81 \pm 2.15$ & \multirow{2}{*}{$\mathrm{P}<0.01$} & 73 & $12.31 \pm 1.42$ & \multirow{2}{*}{ n.s. } & 87 \\
\hline SW & $15.40 \pm 1.62$ & & 61 & $12.68 \pm 1.59$ & & 91 \\
\hline
\end{tabular}

The differences were analyzed using Scheffe's test. n.s. indicates no significant difference at the $5 \%$ level.

\section{DISCUSSION}

The present study indicated that most developmental and reproductive traits examined were similar in the short- and long-winged morphs of L. migratoria. The duration of nymphal development was significantly shorter in the long-winged morph than the short-winged morph of gregarious females in the Tsushima strain. However, the fact that this was not the case in the albino strain may suggest that the difference recorded for the Tsushima strain is not morph-specific. Body weight at adult emergence tended to be lighter in the short-winged than the long-winged morph in the Tsushima strain, although the inter-morph difference was statistically significant only for gregarious males. Unfortunately, adult body weight was not measured for the albino strain in the present study. In a previous study using the same strains of L. migratoria, no significant inter-morph difference was recorded in head width, but other traits such as leg lengths and wing weight were consistently lower in the short-winged morph (Nishide \& Tanaka, 2013). None of the reproductive traits compared in the present study showed a consistent morph-specific difference in the two 
strains tested. Flight experience influences ovarian development in some insects (McAnelly \& Rankin, 1986; Guerra \& Pollack, 2009). In L. migratoria, however, the pre-ovipositional period was similar for female adults housed in large and small cages in which flight was possible and not possible, respectively (Tanaka et al., 1993). Hatchling body weight was significantly lower in the short-winged morph than the long-winged morph of the Tsushima strain, but the difference was not significant for the albino strain, indicating that the difference recorded for the Tsushima strain may not be morph-specific.

The results for the short-winged morph of L. migratoria are in sharp contrast with those for many other species of insects for which there are negative correlations or trade-offs between flight capability and other fitnessrelated traits (Harrison, 1980; Zera \& Denno, 1997). The absence of differences in fitness-related traits of shortand long-winged morphs of L. migratoria might be explained in several ways. One explanation is that there is a yet to be discovered fitness-related trait associated with short wing lengths. A second possibility is that the energy cost of constructing long wings and legs is not large enough to have an effect on other traits. The third possibility is that this short-winged morph is just an aberration, but might represent an initial stage in the evolution of wing dimorphism in this locust and currently there is no genetic correlation with any other trait. As mentioned earlier (Tanaka \& Nishide, 2012a), the short-winged morph of this locust was discovered in laboratory lines that were originally derived from a Tsushima population. Because this wing morph is controlled by a simple recessive Mendelian unit, we cannot exclude the possibility that mutation leading to the appearance of the short-winged morph occurred in the laboratory, as suggested for the shortwinged morph of Oncopeltus fasciatus (Klausner et al., 1981) and Spilostethus pandurus (Solbreck \& Anderson, 1989). However, Tanaka \& Nishide (2012a) mention that this recessive gene is probably present in natural populations and manifested in the laboratory because of inbreeding. Tanaka \& Nishide (2012b) record another unusual phenotype, green hatchling colour in the 2nd generation of an inbred L. migratoria colony.

There are no records of short-winged specimen occurring in natural populations in the original habitat on Tsushima Island, even after intensive search in 2009 (ca. 250 individuals, Tanaka \& Nishide, 2012a) and 2012 (ca. 300 individuals, Tanaka S. \& Tokuda M., unpubl. observ.). Among 31 egg pods, each produced by a different female collected on Minami-Daito Island, Okinawa, Japan in 2012, however, one egg pod gave rise to 2 males that had short wings $(5.1 \%$, total $n=39$; Nishide Y. \& Tanaka S., unpubl. observ.). The ratios of fore wing length to head width of 4.50 and 4.53 for these two males are small, indicating that they can be categorized as short-winged based on the criterion $(<5.25$ in males) used by Tanaka \& Nishide (2012a). Thus, it is highly likely that the short-winged morph of L. migratoria occurs in the field. The recessive nature, together with the lack of flight capability with little or no adaptive correlation with other traits, might explain why the shortwinged morph is not common in nature, although it might persist because it is not easily eliminated.

Roff (1986) proposed that the first step in the evolution of the short-winged morph in insects is inhibition of the tendency to disperse in some individuals of a long-winged population, which is subsequently followed by degeneration of the flight muscles and finally a reduction in wing length. He cites the milkweed bug, $O$. fasciatus, as an example of the first step, in which genetic variation in dispersal ability occurs in this long-winged species (Dingle, 1978, 1980). A second step is that flightless long-winged individuals lose the functional flight muscles, resulting in dimorphism in terms of the development of flight muscles. Flight muscle dimorphism occurs in weevils (Jackson, 1933), chafer beetles (Tada et al., 1994) and silphine beetles (Ikeda et al., 2007). There are many examples of insects with reduced wings in which both dispersal and flight muscle development are inhibited (Roff, 1986), although nothing is known about how these short-winged morphs have evolved. In the cricket, Teleogryllus derelictus, however, these three steps appear to occur at the same time; flight muscle mass at adult emergence is closely correlated with wing length and there is continuous variation in both these traits (Tanaka et al., 2001). Only individuals with long wings are capable of flying and rapid flight muscle histolysis occurs shortly after adult emergence in flightless individuals with short or medium-sized wings. Similar variation occurs in a Tennessee population of the field cricket, Gryllus rubens (Tanaka S., Takeda M. \& Arai T., unpubl. observ.). Roff's hypothesis (1986) does not account for the situation in the short-winged morph of $L$. migratoria, because the short-winged morph of this locust maintains functional flight muscles for at least 30 days after adult emergence, which is similar to that recorded for long-winged adults (Nishide \& Tanaka, 2013). The results presented for L. migratoria might indicate another possible pathway for the evolution of the short-winged morph in insects.

ACKNOWLEDGEMENTS. The authors thank N. Totsuka, M. Higuchi and Y. Yokota for assistance with rearing the locusts at NIASO. Thanks are also due to K. Goto (Okinawa Prefectural Nanbu Agriculture, Forestry and Fisheries Promotion Center) for sending us adult females collected on Minami-Daito Island. This study was supported in part by a Kakenhi grant to S.T. (no. 23380038). The grass used in this experiment was raised by the Field Management Section of NIASO. Two anonymous reviewers greatly improved the manuscript.

\section{REFERENCES}

Ando Y. \& HaRtley J.C. 1982: Occurrence and biology of a long-winged form of Conocephalus discolor. - Entomol. Exp. Appl. 32: 238-241.

Chen Y.-L. 1999: The Locust and Grasshopper Pests of China. China Forestry Publishing House, Beijing, 72 pp.

Danthanarayana W. 1986: Insect Flight: Dispersal and Migration. Springer, Berlin, $289 \mathrm{pp}$.

Denno R.F. \& Grissell E.E. 1979: The adaptiveness of wingdimorphism in the salt marsh-inhabiting planthopper, Pro- 
kelisia marginata (Homoptera: Delphacidae). - Ecology 60: 221-236.

Denno R.F., Olmstead K.L. \& McCloud E.S. 1989: Reproductive cost of flight capability: a comparison of life history traits in wing dimorphic planthoppers. - Ecol. Entomol. 14: $31-44$.

Dingle H. 1978: Migration and diapause in tropical, temperate, and island milkweed bugs. In Dingle H. (ed.): Evolution of Insect Migration and Diapause. Springer, New York, pp. 254-276.

Dingle H. 1980: Ecology of evolution and migration. In Gauthreaux Jr. S.A. (ed.): Animal Migration, Orientation, and Navigation. Academic Press, New York, pp. 1-101.

Dingle H. 1985: Migration. In Kerkut G.A. \& Gilbert L.I. (eds): Comprehensive Insect Physiology, Biochemistry and Pharmacology. Vol. 9. Pergamon Press, New York, pp. 375-415.

Dixon A.F.G. \& HowARD M.T. 1986: Dispersal in aphids, a problem in resource allocation. In Danthanarayana W. (ed.): Dispersal and Migration. Springer, Berlin, pp. 145-151.

Duarte A.J. 1938: Problems of growth of the African Migratory Locust. - Bull. Entomol. Res. 29: 425-456.

FAIRBAIRN D.J. 1988: Adaptive significance of wing dimorphism in the absence of dispersal: a comparative study of the wing morphs in the waterstrider, Gerris remigis. - Ecol. Entomol. 13: $273-281$.

FARROw R.A. \& Colless D.H. 1980: Analysis of the interrelationships of geographical races of Locusta migratoria (Linnaeus) (Orthoptera: Acrididae) by numerical taxonomy, with special reference to sub-speciation in the tropics and affinities of the Australian race. - Acrida 9: 77-99.

FAURE J.C. 1932: The phases of locusts in South Africa. - Bull. Entomol. Res. 23: 293-405.

GuERRA P.A. 2011: Evaluating the life-history trade-off between dispersal capability and reproduction in wing dimorphic insects: a meta-analysis. - Biol. Rev. 86: 813-835.

Guerra P.A. \& Pollack G.S. 2009: Flight behaviour attenuates the trade-off between flight capability and reproduction in a wing polymorphic cricket. - Biol. Lett. 5: 229-231.

HARRISON R.G. 1980: Dispersal polymorphisms in insects. Annu. Rev. Ecol. Syst. 11: 95-118.

HigaKi M. \& ANDo Y. 2003: Effects of crowding and photoperiod on wing morph and egg production in Eobiana engelhardti subtropica (Orthoptera: Tettigoniidae). - Appl. Entomol. Zool. 38: 321-325.

Ikeda H., Kubota K., Kagaya T. \& Abe T. 2007: Flight capabilities and feeding habits of silphine beetles: are flightless species really "carrion beetles"? - Ecol. Res. 22: 237-241.

JACKSON D. 1933: Observations on the flight muscles of Sitona weevils. - Ann. Appl. Biol. 20: 731-770.

KIMURA T. \& MASAKI S. 1977: Brachypterism and seasonal adaptation in Orygyia thyellina Butler (Lepidoptera, Lymantryiidae). - Kontyu 45: 97-106.

Klausner E., Miller E.R. \& Dingle H. 1981: Genetics of brachyptery in a lygaeid bug island population. $-J$. Hered. $\mathbf{7 2}$ 288-289.

Ma C., Yang P., Jiang F., Chapuis M.P., Shali Y., Sword G.A. \& KANG L. 2012: Mitochondrial genomes reveal the global phylogeography and dispersal routes of the migratory locust. - Mol. Ecol. 21: 4344-4358.

McAnelly M.L. \& Rankin M.A. 1986: Migration in the grasshopper Melanoplus sanguinipes (Fab.). II. Interactions between flight and reproduction. - Biol. Bull. 170: 378-392.

MochIDA O. 1973: The characters of the two wing forms of Javesella pellucid (F.) (Homoptera: Delphacidae), with special reference to reproduction. - Trans. R. Entomol. Soc. Lond. 125: 177-225.
Mole S. \& Zera A.J. 1994: Differential resource consumption obviates a potential flight-fecundity trade-off in the sand cricket (Gryllus firmus). - Funct. Ecol. 8: 573-580.

MuraJi M. \& NakasujI F. 1988: Comparative studies on life history traits of three wing dimorphic water bugs, Microvelia spp. Westwood (Heteroptera: Veliidae). - Res. Popul. Ecol. 30: $315-327$.

Nishide Y. \& TANAKa S. 2013: Wing dimorphism in the migratory locust, Locusta migratoria: differentiation of wing morph and phase polyphenism. - Entomol. Sci. in press. doi: 10.1111/ens.12023.

Pener M.P. 1985: Hormonal effects on flight and migration. In Kerkut G.A. \& Gilbert L.I. (eds): Comprehensive Insect Physiology, Biochemistry and Pharmacology. Vol. 8. Pergamon Press, New York, pp. 491-550.

Pener M.P. 1991: Locust phase polymorphism and its endocrine relations. - Adv. Insect Physiol. 23: 1-79.

Pener M.P. \& Simpson S.J. 2009: Locust phase polyphenism: an update. - Adv. Insect Physiol. 36: 1-272.

RanKIN M.A. 1985: Migration: Mechanisms and Adaptive Significance. Contributions in Marine Science 27. University of Texas Press, Austin, 868 pp.

Ritchie M.G., Butlin R.K. \& Hewitt G.M. 1987: Causation, fitness effects and morphology of macropterism in Chlorthippus parallelus (Orthoptera: Acrididae). - Ecol. Entomol. 12: 209-218.

RofF D.A. 1984: The cost of being able to fly: a study of wing polymorphism in two species of crickets. - Oecologia 63: 30-37.

RofF D.A. 1986: The evolution of wing dimorphism in insects. - Evolution 40: 1009-1020.

RofF D.A. \& FaIRBAIRN D.J. 1991: Wing dimorphisms and evolution of migratory polymorphisms among the Insecta. - Am. Zool. 31: 243-251.

SAто T. 1977: Lifehistory and diapause of the white-spotted tussock moth Orgyia thellina Butler (Lepidoptera: Lymantriidae). - Jap. J. Appl. Entomol. Zool. 21: 6-14.

SolBRECK C. 1986: Wing and flight muscle polymorphism in a lygaeid bug, Horvathiolus gibbicollis: determinants and life history consequences. - Ecol. Entomol. 11: 435-444.

Solbreck C. \& Anderson D.B. 1989: Wing reduction; its control and consequences in a lygaeid bug, Spilostethus pandurus. - Hereditas 111: 1-6.

Tada S., Honma K., Kakizaki M. \& Fujisaki K. 1994: Genetic mode of flight muscle dimorphism in a scarabaeid, Heptophylla picea Motschulsky. - Appl. Entomol. Zool. 30: 501-507.

TANAKA S. 1976: Wing polymorphism, egg production and adult longevity in Pteronemobius taprobanensis Walker (Orthoptera: Gryllidae). - Kontyu 44: 327-333.

TANAKA S. 1986: De-alation, flight muscle histolysis, and oocyte development in the striped ground cricket, Allonemobius fasciatus. - Physiol. Entomol. 11: 453-458.

TANAKA S. 1992: The significance of embryonic diapause in a Japanese strain of the migratory locust, Locusta migratoria (Orthoptera: Acrididae). - Jap. J. Entomol. 60: 503-520.

TANAKA S. 1993: Allocation of resources to egg production and flight muscle development in a wing dimorphic cricket Modicogryllus confirmatus. - J. Insect Physiol. 47: 493-498.

TANAKA S. 1999: Resource allocation, metabolic rate and hormonal control of the reproductive organs and flight muscle in male adults of a wing dimorphic cricket, Modicogryllus confirmatus. - Entomol. Sci. 2: 315-327.

TANAKA S. \& NISHIDE Y. 2012a: First record of the occurrence and genetics of a short-winged morph in the migratory locust, 
Locusta migratoria (Orthoptera: Acrididae). - J. Orthopt. Res. 21: 169-174.

TANaKa S. \& Nishide Y. 2012b: A green morph of the migratory locust, Locusta migratoria L. (Orthoptera: Acrididae) that occurred after inbreeding. - J. Orthopt. Res. 21: 175-177.

TANAKA S. \& Wolda H. 1987: Seasonal wing length dimorphism in a tropical seed bug: ecological significance of the short-winged form. - Oecologia 73: 559-565.

TANaka S., HaKomori T. \& Hasegawa E. 1993: Effects of daylength and hopper density on reproductive traits in a Japanese population of the migratory locust, Locusta migratoria L. J. Insect Physiol. 39: 571-581.

Tanaka S., Katagiri C., Arai T. \& Nakamura K. 2001: Continuous variation in wing length and flight musculature in a tropical field cricket, Teleogryllus derelictus: implications for the evolution of wing dimorphism. - Entomol. Sci. 4: 195-208.

Tauber M.J., Tauber C.A. \& Masaki S. 1986: Seasonal Adaptations of Insects. Oxford University Press, New York, 411 pp.

Tokuda M., Tanaka S. \& Zhu D.-H. 2010: Multiple origins of Locusta migratoria (Orthoptera: Acrididae) in the Japanese
Archipelago and the presence of two major clades in the world: evidence from a molecular approach. - Biol. J. Linn. Soc. 99: 570-581.

UTIDA S. 1972: Density dependent polymorphism in the adult of Callosobruchus maculatus (Coleoptera, Bruchidae). - J. Stored Prod. Res. 8: 111-125.

Uvarov B. 1966: Grasshoppers and Locusts. Vol. 1. Cambridge University Press, Cambridge, $x i+481 \mathrm{pp}$.

YAMAGISHI M. \& TANAKA S. 2009: Overwintering biology and morphological characteristics of the migratory locust, Locusta migratoria after outbreaks on Iheya Island, Japan. - Appl. Entomol. Zool. 44: 165-174.

ZERA A.J. 1984: Differences in survivorship, development rate and fertility between longwinged and wingless morphs of the waterstrider, Limnoporus caniculatus. - Evolution 38: $1023-1032$.

Zera A.J. \& Denno R.F. 1997: Physiology and ecology of dispersal polymorphism in insects. - Annu. Rev. Entomol. 42: 207-230.

Received April 15, 2013; revised and accepted June 13, 2013 